Diklus: Jurnal Pendidikan Luar Sekolah, 1(1), Maret 2017 - 20

M. Fasial

\title{
KEPEMIMPINAN KEPALA MADRASAH DINIYAH DI PONDOK PESANTREN WAHID HASYIM SLEMAN YOGYAKARTA
}

\section{THE PRINSIPAL LEADERSHIP OF MADRASAH DINIYAH IN PONDOK PESANTREN WAHID HASYIM SLEMAN YOGYAKARTA}

Oleh : m. faisal, pendidikan luar sekolah, universitas negeri yogyakarta, faisalsukses1212@gmail.com

\begin{abstract}
Abstrak
Penelitian ini bertujuan untuk mendiskripsikan: 1) Bentuk Pelaksanaan Madrasah Diniyah; 2) Kepemimpinan Kepala Madrasah Diniyah; 3)Faktor pendukung dan penghambat Kepemimpinan Kepala Madrasah Diniyah. Penelitian ini merupakan penelitian Kualitatif deskriptif. Informan penelitian adalah Kepala Madrasah Diniyah, Ustadz/pengelola Madrasah Diniyah, Pengurus, dan Santri di Pondok Pesantren Wahid Hasyim. Pengumpulan data dilakukan dengan menggunakan metode observasi, wawancara, dan dokumentasi. Adapun tehnik yang digunahkan dalam analisis data adalah display data, reduksi data dan pengambilan kesimpulan. Trianggulasi yang dilakukan dengan menggunahkan trianggulasi sumber. Hasil penelitian menunjukkan bahwa 1) Madrasah Diniyah merupakan lembaga pendidikan nonformal pesantren tingkat dasar dan menengah dengan kurikulum agama islam yang diajarkan melalui Kutubut tsurat. Mempunyai 4 jenjang jenjang pendidikan yaitu I'dadiyah(dasar), ula (awal), wustha(menengah) dan ulya (tinggi). 2) Kepala Madrasah Diniyah cenderung menggunakan kepemimpinan parsitipatif yang lebih mengutamakan musyawarah serta merangkul setiap anggotanya. Komunikasi yang digunakan ada 2 cara yaitu global dan individual. Dalam melaksanakan tugasnya Kepala Madrasah Diniyah santai tetapi serius dan juga dikenal disiplin. 3) Faktor pendukung: Madrasah Diniyah berada di lingkungan pesantren, adanya kerjasama yang baik antar lembaga, para ustadz berlatar pendidikan yang bagus, tingkat kepercayaaan santri dan pihak lain yang tinggi. Faktor penghambat: gedung merupakan milik yayasan yang digunakan bersama oleh semua lembaga, itu masih adanya rasa pekewuh terhadap santri senior dan terdapat beberapa santri yang juga aktif di lembaga lain
\end{abstract}

Kata kunci : Kepemimpinan, Madrasah Diniyah

\section{Abstract}

This study aimed to describe: 1) Form of Implementation Madrasah Diniyah; 2) Leadership Principals Diniyah; 3) The factors supporting and Leadership Principals Diniyah. This research is qualitative descriptive. The informants are Principals Madrasah Diniyah, Ustadz / manager Madrasah Diniyah, the Manegement and Student in Pondok Pesantren Wahid Hasyim. The data collection is done by using the method of observation, interviews, and documentation. The techniques used in data analysis is the display of data, data reduction and conclusions. Triangulation is done with source triangulation of data. The results showed that 1) Madrasah Diniyah a non-formal educational institution elementary and secondary schools with Islamic religious curriculum is taught through Kutubut tsurat Have 4 levels of education are I'dadiyah (basic), ula (early), Wustha (medium) and ulya (high). 2) Principals Diniyah tend to use a participatory leadership that prefers consensus and embrace each of its members. Communication used there are 2 ways global and individual. In performing its duties Principals Diniyah relaxed but serious and well known discipline. 3) Supporting factors: Madrasah Diniyah were in boarding schools, good cooperation between institutions, religious teachers set a good education, kepercayaaan level students and others high. Inhibiting factors: the building is owned by a foundation that is shared by all institutions, it is still the awe of the senior students, and there are some students who are also active in other institutions

Keyword: Leadership, Madrasah Diniyah 


\section{PENDAHULUAN}

Pondok Pesantren adalah lembaga pendidikan Islam pertama di Indonesia dan merupakan salah satu model dari pendidikan berbasis masyarakat. Mayoritas Pondok Pesantren berdiri atas inisiatif masyarakat muslim yang utamanya untuk mendidik generasi muda agar memahami dan mengamalkan ajaranajaran Islam dengan baik (Zubaedi, 2007:140) Senada dengan pendapat Adhi Iman S, dkk (2014: 110), pesantren memiliki konsep keseimbangan pendidikan moral (batin) dan sosial serta ekonomi (lahir) merupakan filosofi bahwa Islam sebagai rahmat bagi seluruh alam (Rahmatan Lil'aalamiin). Sebelum Indonesia merdeka lembaga Pesantren sudah ada lama di Indonesia hanya saja dahulu berawal dari masjid sebagai tempat untuk belajar agama. Berjalannya waktu berkembang menjadi sistem asrama. para murid di Pondok Pesantren disebut Santri atau Santriwati, mereka tinggal disana selama beberapa waktu untuk mencari ilmu agama di Pondok Pesantren.

Madrasah Diniyah merupakan salah satu lembaga pendidikan keagamaan nonformal yang banyak diselenggarakan dibawah yayasan Pondok Pesantren. Oleh karena itu Madrasah Diniyah juga harus senantiasa dilaksanakan dengan baik. Berdasarkan pengamatan awal peneliti, diperoleh gambaran bahwa Madrasah Diniyah yang diselenggarakan dalam Pondok Pesantren . lembaga Madrasah Diniyah tersebut juga mempunyai payung hukum yang ditegaskan di dalam pasal 30 ayat 4 UU No 20/2003 yang menyatakan bahwa "pendidikan keagamaan berbentuk Pendidikan Madrasah Diniyah, Pesantren, Pasraman, Pabbajja Samanera dan bentuk lain yang sejenis"

$$
\text { Kepemimpinan seseorang dalam }
$$
sebuah organisasi sangat besar pengaruhnya dalam setiap pengambilan keputusan. Pengambilan keputusan dalam tinjauan perilaku mencerminkan karakter bagi seorang pemimpin oleh sebab itu, baik atau tidaknya keputusan yang diambil tidak hanya dinilai dari konsekuensi yang ditimbulkannya, tetapi juga melalui berbagai pertimbangan dalam prosesnya Kepala Madrasah Diniyah adalah Pemimpin Madrasah Diniyah, seperti halnya Kepala Madrasah Diniyah di Pondok Pesantren Wahid Hasyim. dari pengamatan peneliti Kepemimpinan Kepala Madrasah Diniyah belum optimal mengingat Lembaga Madrasah Diniyah ini berada dibawah Yayasan menjadikan sebagian besar mengikuti aturan Yayasan Pondok Pesantren Wahid Hasyim. Lingkungan Pondok Pesantren sebenarnya mendukung Madrasah diniyah dalam Pengelolaannya untuk memperoleh Input SDM dan suasana belajar yang baik

Proses kepemimpinan kepala Madrasah Diniyah di Pondok Pesantren sangat penting, karena kita ketahui kepemimpinan dalam organisasi sangat penting dan tidak dapat ditawar sebab pemimpin mempunyai andil 
Diklus: Jurnal Pendidikan Luar Sekolah, 1(1), Maret 2017 - 22

M. Fasial

dalam menentuhkan tercapainya atau tidaknya

tujuan organisasi

Kepemimpinan kepala Madrasah

Diniyah harusnya dapat mempengaruhi para ustadz dan santri dalam menjalankan kegiatan Madrasah Diniyah tersebut. Hal lain yang tidak kalah penting adalah serangkaian harga diri, nilai-nilai yang didasarkan pada standar kesempurnaan yang tertinggi yang mungkin diraih. Sebagian nilai yang paling memiliki sifat pemberdayaan diri adalah integritas, kejujuran , kepercayaan, sikap optimis, tanggung jawab pribadi menghormati semua pihak dan terbuka terhadap perubahan. nilai nilai ini membawa dampak terhadap semua pihak. Maka Peneliti tertarik untuk mengangkat penelitian yang berjudul "Kepemimpinan Kepala Madrasah Diniyah di Pondok Pesantren Wahid Hasim Sleman Yogykarta".

\section{METODE PENELITIAN}

\section{Jenis Penelitian}

Penelitian ini menggunakan pendekatan kualitatif deskriptif. pendekatan kualitatif adalah yang tidak menggunahkan dasar dan kerja secara statistik, tetapi secara bukti kualitatif yaitu unsur inovasi baik bersama baik kronologi maupun leksikal yang dimiliki oleh suatu kelompok bahasa tertentu secara eksklusif (M.Hari Wijaya : 2007 :69).

\section{Setting Penelitian}

Penelitian dilaksanakan di Desa Gaten, kelurahan Condong Catur, kecamatan Depok, kabupaten Sleman Yogyakarta tepatnya di Pondok Pesantren Wahid Hasyim

\section{Subjek Penelitian}

Pengambilan sumber data penelitian ini menggunahkan teknik purpose sampling. Adapun Subjek penelitian terdiri dari Kepala Madrasah Diniyah, pengurus Pondok Pesantren Wahid hasyim, ustadz / pengelola Madrasah Diniyah, Santri/wati

\section{Data Instrumen dan Tehnik Pengumpulan Data}

Pada penelitian ini data berupa deskripsif yang diambil dari hasil Observasi, Wawancara dan Dokumentasi. Instrumen utama yang digunahkan dalam penelitian ini adalah Peneliti sendiri yang dibantu pedoman wawancara, pedoman observasi dan pedoman dokumentasi tersruktur yang dibuat sendiri oleh peneliti. Tehnik pengumpulan data yang digunahkan yaitu observasi, wawancara dan dokumentasi.

\section{Teknik Analisi Data}

Tehnik analisis data yang digunahkan dalam penelitian ini adalah deskriptif kualitatif artinya data yang diperoleh dalam penelitian dilaporkan apa adanya kemudian diintrepretasikan secara kualitatif untuk mengambil kesimpulan . Analisis data merupakan cara mengorganisasikan data ke dalam ketegori, menjabarkan ke dalam unit unit, melakukan sintesa, menyusun ke dalam pola, memilih mana yang penting dan yang akan dipelajari dan membuat kesimpulan sehingga mudah dipahami oleh diri sendiri maupun ornag lain (Sugiono, 2011:244). Tehnik analisis data 
yang digunakan yaitu reduksi data, penyajian data dan penarikan kesimpulan.

\section{HASIL DAN PEMBAHASAN}

\section{Bentuk Madrasah Diniyah di Pondok Pesantren Wahid Hasyim}

Madrasah Diniyah di Pondok Pesantren Wahid Hasyim adalah salah satu lembaga non formal di Pondok Pesantren Wahid Hasyim yang bergerak dibidang pembelajaran Agama atau Dirosah Islamiyah dengan menggunahkan materi berbasis kutubuz tzurat (kitab kuning)

Jenjang pendidikan di Madrasah Diniyah mempunyai 4 tingkatan yaitu kelas I'dadiyah (dasar), kelas Ula (awal), kelas wustho (menengah dan kelas Ulya (tinggi). Madrasah Diniyah Wahid Hasyim dikhususkan untuk para Mahasiswa mengingat di yogyakarta tempat kota pelajar yang mempunyai banyak mahasiswa, sistem mengajinya pun juga mengikuti sistem persekolahan yaitu menggunahkan sistem semester.

\section{Kepemimpinan Kepala Madrasah Diniyah}

a. Kepala Madrasah Diniyah dalam mengambil keputusan dan memecahkan masalah

Kepala Madrasah Diniyah di Pondok Pesantren Wahid Hasyim merupakan pribadi yang cepat tanggap dan lincah dalam segala hal sehingga setelah adanya keputusan maka perkembangan masalah yang ada menjadi lebih baik, cepat tertangani selalu terselesaikan sampai tuntas dan berjalan lancar. Selain itu keterlibatan Kepala Madrasah Diniyah sangat penting dalam rapat yaitu dalam pengambilan keputusan rapat yang telah di musyawarahkan, oleh karena itu kepala Madrasah Diniyah mengusahakan selalu hadir dalam setiap rapat. Sering sekali kepala Madrasah Diniyah mengadakan rapat secara dak dakan dikarenakan ada informasi yang harus dimusyawarahkan dengan para pengurus lain. Untuk memudahkan berkoordinasi pihak Madrasah Diniyah membuat groub di media sosial untuk memudahkan dalam berkomunikasi.

b. Cara Kepala Madrasah Diniyah dalam menggerakkan atau memimpin Rekan Kerja

Cara Kepala Madrasah Diniyah dalam menggerakkan atau memimpin Rekan Kerja (ustadz atau santri) dapat dilakuhkan dalam berbagai cara antara lain pembinaan secara langsung terhadap Rekan Kerja, dengan prinsip kekeluargaaan kepala Madrasah Diniyah memberi contoh terlebih dahulu sebelum memerintah, memberi penghargaan khusus kepada santri yang berprestasi dan partisipasi kepala Madrasah Diniyah dalam kegiatan Madrasah Diniyah

c. Kepribadian Kepala Madrasah Diniyah di Pondok Pesantren Wahid Hasyim

Kepribadian yang dimiliki kepala Madrasah Diniyah dalam memimpin Madrasah Diniyah adalah disiplin dalam 
segala hal, percaya diri, saling memotivasi antar sesama. Bapak NA sebagai kepala Madrasah Diniyah selalu santai tetapi serius hal tersebut tampak di dalam dan diluar Madrasah Diniyah

d. Bentuk Komunikasi Kepala Madrasah Diniyah dengan rekan Kerja (Ustadz) dan Santri

Cara kepala madrah Diniyah dalam berkomunikasdi dengan Rekan Kerja yaitu dengan mendatangi langsung siapapun yang ingin diajak bicara, baik ustadz maupun santri . pada saat berkomunikasi kepada Rekan Kerja mendapat respon positif ,baik dapat menerima dengan ikhlas dan menghargai lawan bicara.

kepala Madrasah Diniyah menggunahkan komunikasi formal dan informal dikarenakan selain Bapak kepala memanfaatkan Madrasah Diniyah sebagai wadah komunikasi prinsip kekeluargaaan masih tetap dipakai dan kadang diluar lembaga tersebut masih melakuhkan komunikasi.

e. Sikap Kepala Madrasah Diniyah dalam menerima masukan

Sikap kepala Madrasah Diniyah dalam menerima masukan seperti menerima kritik, saran dan pendapat dari Rekan Kerja yaitu selalu barsikap baik, menerima dengan ikhlas dan lapang dada. Setelah menerima masukan berupa kritik, saran atau pendapat, reaksi yang ditunjukkan cukup baik, santai dan menampung semua pendapat,. Namun semua itu difikirkan terlebih dahulu menerima dan sangat mempertimbangkan segala masukan yang ada, semua masukan akan dipertimbangkan lewat rapat dan dicari solusinya. jika itu baik bagi Madrasah Diniyah maka akan diterima dan dilaksanakan, namun jika belum baik sebatas ditampung saja

\section{Faktor pendukung dan penghambar}

Faktor pengdukung dan penghambat Kepemimpinan kepala Madrasah Diniyah sendiri dibagi menjadi 2 yaitu faktor faktor yang bersal dari pondok Pesantren dan Madrasah Diniyah.

Sedangkan Faktor pendukung dan penghambat dari pondok pesantren berupa lingkungan yang mendukung karena berada di dalam komplek Pondok Pesantren, adanya kerjasama yang baik antara lembaga di pondok yang mendukung satu sama lain, sedangkan untuk faktor penghambat dari pondok pesantren sendiri adalah gedung merupakan milik yayasan yang digunahkan bersama oleh semua lembaga jadi bukan milik lembaga dan juga terdapat beberapa santri yang juga aktif di lembaga lain di dalam Pondok Pesantren Wahid Hasyim

Sedangkan Faktor pendukung dari Madrasah Diniyah adalah Para pengurus dan ustadz mempunyai latar belakang pendidikan yang bagus dan juga tingkat kepercayaan yang tinggi dari santri lain terhadap Kepala madrasah Diniyah tersebut sedangkan untuk faktor penghambatnya yaitu masih terdapat rasa Pekewuh dari kebanyaka santri kepada para seniornya termasuk Kepala Madrasah Diniyah. 
Diklus: Jurnal Pendidikan Luar Sekolah, 1(1), Maret 2017 - 25

M. Fasial

\section{SIMPULAN DAN SARAN}

\section{Simpulan}

Berdasarkan dari hasil penelitian mengenai Kepemimpinan kepala Madrasah Diniyah di Pondok Pesantren Waid hasyim dapat disimpulkan bahwa

1. Lembaga Madrasah Diniyah di pondok Pesantren merupakan lembaga pembelajaran Agama islam yang berada dibawah yaaysan Pondok Pesantren Wahid hasyim yang mempunyai 4 jenjang pendidikan. Para santri di Madrasah Diniyah tersebut diperuntukkan untuk Mahasiswa

2. Kepemimpinan Kepala Madrasah Diniyah di pondok Pesantren Wahid hasyim adalah dalam pengambilan keputusan dan pemecahan masalah selalu dilakuhkan dengan cara musyawarah, dalam menggerakkan anggotanya dengan cara pembinaan langsung baik global maupun individual, sedangkan untuk kepribadian Kepala Madrasah Diniyah adalah pribadi yang disiplin dan saling memotivasi antar sesama. Bentuk komunikasi yang digunahkan dalam keseharian di Madrasah Diniyah terlihat sangat baik, santai, ramah, sopan, santun dan berwibawa dalam berkomunikasi bahasa yang digunahkan dalah bahwa yang sopan dan mudah difahami oleh lawan bicara. Adapun sikab Kepala madrasah Diniyah dalam menerima masukan selalu diterima kritik, saran dan pendapat dari siapa saja yang sifatnya membangun
Faktor pendukung dari pondok pesantren adalah Madrasah Diniyah berada di dalam lingkungan pondok pesantren, terdapat kerjasama yang baik antara lembaga di pondok yang mendukung satu sama lain sedangkan untuk faktor penghambat adalah gedung merupakan milik yayasan yang digunahkan bersama oleh semua lembaga jadi bukan milik lembaga dan juga terdapat beberapa santri yang juga aktif di lembaga lain di dalam Pondok Pesantren Wahid Hasyim

Faktor pendukung dari Madrasah Diniyah adalah Para pengurus dan ustadz mempunyai latar belakang pendidikan yang bagus dan juga tingkat kepercayaan yang tinggi dari santri lain terhadap Kepala madrasah Diniyah tersebut sedangkan untuk faktor penghambatnya yaitu masih terdapat rasa kurang nyaman dari kebanyaka santri kepada para seniornya termasuk Kepala Madrasah Diniyah.

\section{Saran}

1. Bagi Kepala Madrasah Diniyah

a. Kepala Madrasah Diniyah hendaknya lebih meningkatkan perannya dalam memimpin Madrasah Diniyah.

b. Kepala Madrasah Diniyah hendaknya senantiasa melaksanaan pembinaan kepemimpinan kepala pengelola maupun ustad Madrasah Diniyah

c. Kepala Madrasah Diniyah hendaknya tidak segan untuk memberikan pujian atas hasil kerja para Ustadz dan segenap 
Diklus: Jurnal Pendidikan Luar Sekolah, 1(1), Maret 2017 - 26

M. Fasial

pengurus Madrasah Diniyah atas hasil Zubaedi, 2007. Pemberdayaan Masyarakat kerja mereka serta memberikan berbasis Pesantren; Kontribusi Fiqih sosial Kiai Sahal Mahfudz dalam pengarahan dalam mengerjakan suatu perubahan nilai-nilai Pesantren. Penerbit pekerjaan. : Pustaka Pelajar, Yogyakarta

2. Bagi Ustad Madrasah Diniyah

a. Ustadz hendaknya lebih meningkatkan perannya dalam melaksanakan pembelajaran Agama

b. Ustad lebih meningkatkan komunikasi dengan ustad lain terkait pengelolaan Madrasah Diniyah

3. Bagi Madrasah Diniyah

a. Madrasah Diniyah hendaknya meningkatkat sarana dan prasarana guna menunjang pembelajaran santri

b. Madrasah Diniyah hendaknya selalu memantau pelaksanaan program agar tujuan program dapat tercapai dengan baik

\section{DAFTAR PUSTAKA}

Adhi Iman S, dkk. (2016). Pemberdayaan Koperasi Pondok Pesantren Sebagai Pendidikan Sosial Dan Ekonomi Santri. Diakses dari http://journal.uny.ac.id/index.php/jppm pada tanggal 24 Februari 2017, jam 21.42.

Depdiknas. (2003). Undang Undang Republik Indonesia Nomor 20 Tahun 2003 tentang Sisstem Pendidikan Nasional. Jakarta: Depdagri

M.Hari Wijaya. (2007). Metodologi dan tehnik Skripsi, Tesis dan Disertasi. Yagyakarta: Tugu Publiser.

Sugiyono, (2011). Metode Penelitian Pendidikan Pendekatan Kuantitatif dan Kualitatif, dan $R \& D$. Bandung:alfabetta 